\title{
Grand Challenges in Wind Engineering: Advancing Cyber-Physical Tools to Investigate Structural Performance of Buildings
}

\author{
Forrest J. Masters* \\ Engineering School of Sustainable Infrastructure \& Environment, University of Florida, Gainesville, FL, USA
}

Keywords: wind engineering, full-scale testing, computational fluid dynamics, model-in-the-loop, windstorms

\section{INTRODUCTION}

Identifying the next challenges for wind engineering is a highly active topic. In the last year, the American Society of Civil Engineers convened a national meeting on the Future of Wind Engineering to discuss emerging and trending topics. The National Science Foundation has reimagined the Network for Earthquake Engineering Simulation as the Natural Hazards Engineering Research Infrastructure program to promote collaboration over the next decade between the earthquake engineering community and its counterparts in severe weather (tropical cyclones, thunderstorms, and tornadoes). The National Institute of Standards and Technology is also launching strategic planning for the National Windstorm Impact Reduction Program.

The reason for this increased interest in wind engineering stems from, in part, the globally escalat-

OPEN ACCESS

Edited by:

Gregory Alan Kopp,

University of Western

Ontario, Canada

Reviewed by:

Shuyang Cao,

Tongji University, China

*Correspondence: Forrest J. Masters masters@ce.ufl.edu

Specialty section: This article was submitted to Wind Engineering and Science,

a section of the journal Frontiers in Built Environment

Received: 27 February 2016

Accepted: 26 July 2016

Published: 09 August 2016

Citation:

Masters FJ (2016) Grand Challenges

in Wind Engineering: Advancing

Cyber-Physical Tools to Investigate

Structural Performance of Buildings.

Front. Built Environ. 2:18.

doi: 10.3389/fbuil.2016.00018 ing loss of property during extreme wind events. Windstorms caused $\$ 18.4 \mathrm{~B}$ in insured losses in 2014 alone (Swiss Re, 2015). The population at the coast continues to rise, which in the long-term will force greater attention on sheltering in place to combat congested evacuation. Tornado outbreaks occurring during the last 5 years are also shifting the mindset of engineers and decision makers about performance expectations for buildings in mid latitude regions that are prone to thunderstorms and tornadoes. Multi-objective design philosophies [e.g., van de Lindt et al. (2013)] adapted from the seismic engineering community may eventually complement the current approach, which largely rests on linear-elastic analysis and ignores the collapse limit state.

The Grand Challenge is to broadly advance computational wind engineering and to develop cyber-physical methods to investigate the performance of civil infrastructure systems in the context of structural wind loading. The short-term goal is to reduce the reliance of the wind engineering field on physical testing, both and model- and full-scale, and in the long-term, to open new pathways to solving large-scale problems efficiently and accurately through computational methods. The timing to make contributions to the field of wind engineering has never been better, irrespective of the domain expertise brought to bear to find solutions. The wind engineering community is primarily a mix of civil and mechanical engineers, engineering mechanics, and atmospheric scientists. There is ample room for new minds and perspectives originating from outside the discipline. Building physics/science, material science, optimization, and cognitive computing are but a few of the areas outside wind engineering that can contribute.

\section{REDUCING OUR RELIANCE ON PHYSICAL TESTING}

Modern wind engineering relies almost exclusively on experimental testing to quantify wind loading, overall building response, and performance of non-structural components and cladding. Since the 1950s, wind engineering (née industrial aerodynamics) has employed atmospheric boundary layer wind tunnels (BLWT) to quantify pressure loads on the building surface, base reactions for foundation 
design, and the aerodynamic response of wind-sensitive structures. BLWT modeling is complemented by standardized testing procedures to evaluate the resistance of component and cladding under the action of wind loading or wind-driven rain (e.g., ASTM methods to evaluate the water penetration resistance of curtain wall assemblies or missile impact testing to simulate the effects of windborne debris).

Following notable tropical cyclones in the 1980s and early 1990s (e.g., Tracy, Hugo, and Andew), the wind engineering community initiated development of full-scale testing apparatuses to evaluate the system-level performance of real, constructed building mockups at full scale or large scale (cf. Kopp et al., 2012). These facilities create holistic simulations of windstorm environments to (a) fill the experimental "gap" between BLWT modeling and product approval test standards that apply simplified load conditions to a single component and (b) provide the versatility to study a broader class of problems, including ember transport, hail, and wind-driven rain. The largest of the wind-tunnel type facilities is located at the Insurance Institute for Business \& Home Safety in South Carolina (Morrison et al., 2012). At 30 MW, it is the largest and most powerful wind (engineering) tunnel in the world. Other facilities include the Jules Verne climatic wind tunnel at the Centre Scientifique et Technique du Bâtiment in France and the Florida International University Wall of Wind (Huang et al., 2009). Tokyo Tech University is currently planning to build a 90+ MW facility of similar design in Japan. Collectively, the establishment of these facilities has brought the experimental capabilities in wind engineering on par with the seismic and blast engineering communities, which use large-scale shaking tables and shock tubes to replicate their respective hazard effects.

The combined experimental capabilities for model-, component-, and full-scale testing of wind engineering labs worldwide stems from a 50+ year culmination of effort to improve our physical understanding of extreme wind load effects on building systems. Growth in experimental testing capabilities in the last decade has been prolific, and the community is on track to solve a wide range of long-standing problems, e.g., development of physics-based fragility models for loss estimation that are calibrated to experimental test results. It is assumed that these open questions will be addressed in due time. Here, we focus on what will follow, rising to the challenge issued by Theodore Sturgeon, "Ask the next question, and the one that follows that, and the one that follows that." Specifically, it seeks to promote research that will build on, enhance, or eventually replace the experimental methods of today.

\section{ADVANCING CYBER(PHYSICAL) WIND ENGINEERING RESEARCH}

The wind engineering community's reliance on physical testing can be attributed in part to the present inability of computational fluid dynamics (CFD) methods (e.g., large-eddy simulation) to accurately capture peak pressures in the separated flow region on a bluff-body or flow over complex terrains (Cochran and Derickson, 2011). Efforts to create a "virtual wind tunnel" have largely been decried in the literature (Stathopoulos, 2002; Blocken, 2014) despite steady advances over the last three decades (Murakami, 1977; Stathopoulos, 1997; Blocken, 2014). Löhner et al. (2015) argues that modeling of bluff-body aerodynamics and fluid-structure interaction has lagged aerospace and naval engineering (which widely use CFD) because of the inherent computational expense arising from more complicated physics (e.g., the flow field around bluff bodies, non-linear deformation of flexible structures). The present author argues that we should not view this as an immovable roadblock in the near future but rather a worthy problem, a high priority for the field, and a rallying point for coordinated research efforts.

Applying purely computational methods to calculate loads, and even further still to perform coupled fluid/structural analysis, is still far out on the horizon. However, developing (real-time) hybrid experimental/computational methods (i.e., "model-inthe-loop" approaches) is a critical, evolutionary step forward in reaching this goal. Adoption of these methods is growing (cf. Meroney, 2004, 2016), although applications generally center on validating/informing rather than iteratively updating each other, as in the case in the earthquake engineering paradigm. For example, CFD methods can improve the design and execution of experiments or, in special cases, fully complement experimental analysis, e.g., the study of pedestrian-level wind comfort or winddriven rain impinging on a building.

However, the scope of this grand challenge extends beyond cross-validation. It looks to the wind engineering community to develop (real-time) hybrid simulation techniques for structural engineering problems in wind engineering. The classical approach to hybrid simulation is to partition a structural system (e.g., a reinforced concrete frame building) into a computational model and a subset of the structure that is tested experimentally using closed-loop controls to apply displacement or loads at the boundary conditions. The resultant feedback (load or displacement) updates the computational model at each time step; therefore, it is possible to simulate the global behavior of the structure, while accurately capturing the behavior of the component, even as it exhibits non-linear behavior (Gómez et al., 2014). While the value of this approach has yet to be determined for wind engineering, the approach is undeniably new and potentially could advance both full-scale and model-scale testing. The latter is particularly interesting because hybrid simulation for seismic engineering usually experimentally tests a substructure and evaluates the remainder of the structure numerically using a fast running finite element (FEA) analysis. In wind engineering, the process could be reversed, i.e., the aeroelastic behavior of an idealized geometrically scaled, wind-sensitive structure can be evaluated experimentally in the BLWT, while complementary FEA analysis assesses measures of strength and serviceability. Coupled with control systems that change the shape or modify mass, stiffness or damping in the model, and the solution domain scales to include optimal design of that class of structure.

\section{SUMMARY}

The last half century has brought significant and foundational advancements in wind engineering, but the field still remains heavily reliant on experimental methods to conduct research and perform rational analysis for the design of infrastructure in areas prone to strong winds. Recent developments in full-scale wind 
engineering have brought experimental facilities on par with counterparts in seismic and blast engineering; however, the gulf between physical testing and computational wind engineering is still large. Investing effort into improving CFD methods and hybrid (cyber-physical) simulation could bring these efforts full circle and reduce the reliance on expensive and time-consuming efforts to physically reproduce severe weather phenomena and capture the behavior of representative building systems. These efforts are necessary to reduce the loss of life and property during extreme wind events and ultimately make communities more resilient to thunderstorms, tornadoes, and tropical cyclones.

\section{REFERENCES}

Blocken, B. (2014). 50 years of computational wind engineering: past, present and future. J. Wind Eng. Ind. Aerod. 129, 69-102. doi:10.1016/j.jweia.2014.03.008

Cochran, L., and Derickson, R. (2011). A physical modeler's view of computational wind engineering. J. Wind Eng. Ind. Aerod. 99, 139-153. doi:10.1016/j. jweia.2011.01.015

Gómez, D., Dyke, S. J., and Maghareh, A. (2014). "On the role of hybrid and realtime hybrid simulations in advancing the practice of earthquake engineering," in 6th World Conference on Structural Control and Monitoring, July 15-17, Barcelona.

Huang, P., Chowdhury, A. G., and Bitsuamlak, G. (2009). Development of devices and methods for simulation of hurricane winds in a full-scale testing facility. Wind Struct. 12, 151-177. doi:10.12989/was.2009.12.2.151

Kopp, G. A., Morrison, M. J., and Henderson, D. J. (2012). Full-scale testing of low-rise, residential buildings with realistic wind loads. J. Wind Eng. Ind. Aerod. 104-106, 25-39. doi:10.1016/j.jweia.2012.01.004

Löhner, R., Haug, E., Michalski, A., Muhammad, B., Drego, A., Nanjundaiah, R., et al. (2015). Recent advances in computational wind engineering and fluid-structure interaction. J. Wind Eng. Ind. Aerod. 144, 14-23. doi:10.1016/j. jweia.2015.04.014

Meroney, R. N. (2004). "Wind tunnel and numerical simulation of pollution dispersion: a hybrid approach," in Lecture Series Proceeding from the Croucher Advanced Study Institute, Hong University of Science and Technology, 6-10 December 2004, Fort Collins, CO.

Meroney, R. N. (2016). Ten questions concerning hybrid computational/physical model simulation of wind flow in the built environment. Build. Environ. 96, 12-21. doi:10.1016/j.buildenv.2015.11.005

\section{AUTHOR CONTRIBUTIONS}

The author confirms being the sole contributor of this work and approved it for publication.

\section{ACKNOWLEDGMENTS}

The author wishes to acknowledge the National Science Foundation Natural Hazards Engineering Research Infrastructure Program (Award No. 1520843). Any opinions expressed are solely his own.

Morrison, M. J., Brown, T. M., and Liu, Z. (2012). "Comparison of field and fullscale laboratory peak pressures at the IBHS Research Center," in Proc. ATC-SEI Advances Hurricane Eng. Conf, Miami, FL.

Murakami, S. (1977). Current status and future trends in computational wind engineering. J. Wind Eng. Ind. Aerod. 67\&68, 3-24.

Stathopoulos, T. (1997). Computational wind engineering: past achievements and future challenges. J. Wind Eng. Ind. Aerod. 67-68, 509-532. doi:10.1016/ S0167-6105(97)00097-4

Stathopoulos, T. (2002). The numerical wind tunnel for industrial aerodynamics: real or virtual in the new millennium? Wind Struct. 5, 193-208. doi:10.12989/ was.2002.5.2_3_4.193

Swiss Re. (2015). "Natural catastrophes and man-made disasters in 2014: convective and winter storms generate most losses," in Sigma, No. 2. Available at: http://www.swissre.com/sigma/

van de Lindt, J., Pei, S., Dao, T., Graettinger, A., Prevatt, D., Gupta, R., et al. (2013). Dual-objective-based tornado design philosophy. J. Struct. Eng. 139, 251-263. doi:10.1061/(ASCE)ST.1943-541X.0000622

Conflict of Interest Statement: The author declares that the research was conducted in the absence of any commercial or financial relationships that could be construed as a potential conflict of interest.

Copyright (C) 2016 Masters. This is an open-access article distributed under the terms of the Creative Commons Attribution License (CC BY). The use, distribution or reproduction in other forums is permitted, provided the original author(s) or licensor are credited and that the original publication in this journal is cited, in accordance with accepted academic practice. No use, distribution or reproduction is permitted which does not comply with these terms. 